As the table shows, parkinsonism can be induced even by daily doses of cinnarizine of less than $150 \mathrm{mg}$. Patients with tremor tended to be younger (MannWhitney U test, $p=0.0043$ ), however, and seemed to have taken lower cumulative doses than those with parkinsonism (Mann-Whitney $U$ test, $p=0.0417$ ). Patients with flunarizine induced parkinsonism (median age 63) were younger than those affected by cinnarizine (median age 78) (Mann-Whitney $U$ test, $p=0.0059$ ), and these differences were apparently not related to different indications for the use of each drug.

Cinnarizine and flunarizine are piperazine derivatives structurally related to some phenothiazines, and this may explain their extrapyramidal effects. Their calcium channel blocking activity may also contribute to this effect. We have started a case-control study with the aim of quantifying the risk of extrapyramidal disorders associated with these drugs.

1 Martí Massó JF, Carrera N, de la Puente E. Posible parkinsonismo por cinaricina. Med Clin (Barc) 1985;85:614-6.

2 Chouza C, Scaramelli A, Caamaño JL, De Medina O, Aljanati R, Romero S. Parkinsonism, tardive dyskinesia, akathisia, and depression induced by flunarizine. Lancet 1986;i:1303-4.

3 Meyboom RHB, Ferrari MD, Dieleman BP. Parkinsonism, tardive dyskinesia, akathisia, and depression induced by flunarizine. Lancet 1986;ii:292.

4 Joint Formulary Committee. British national formulary number 14 . London British Medical Association and The Pharmaceutical Society of Great Britain, 1987:160.

5 Laporte JR, Capellà D. Useless drugs are not placebos: lessons from flunarizine and cinnarizine. Lancet 1986;ii:853-4.

(Accepted 9 May 1988)

\section{Dangerous oronasal obstruction in weak senile patients}

\section{A M M Berkhout, $\mathrm{H}$ J M Cools}

de Bieslandhof Nursing and Rehabilitation Centre, 2612 VC Delft, The Netherlands A M M Berkhout, MD, physician

$\mathrm{H} \mathrm{J}$ M Cools, MD, adjunct director

Correspondence to: $\mathrm{Dr}$ Cools.

During routine surveillance in this 320 bed nursing centre patients are sometimes found in a dangerous condition of dyspnoea and cyanosis. We describe five cases in which this condition was caused by oronasal obstruction.

\section{Case reports}

Case 1-An 85 year old woman with severe Alzheimer's disease was emaciated, drank little, and remained bedridden; she was receiving no drugs. She was found in a dangerous dyspnoeic and cyanotic state; the nostrils were sucked in during inspiration but a certain degree of inspiration was audible. Attempts to open the tightly closed mouth met with little success and were repelled by the patient. There was a deviated nasal septum swelling of the mucosa. A disposable catheter (Charrière $12,13 \mathrm{~cm}$ long) was inserted into the smaller nostril. Dyspnoea and cyanosis resolved within several minutes, at which time the patient opened her mouth spontaneously. She had neither teeth nor dentures. The nasal catheter was removed several hours later. There was no recurrence.

Case 2-A 76 year old woman with severe Alzheimer's disease was dehydrated and wasted; she was receiving $50 \mathrm{mg}$ pentazocine four times daily as an analgesic. Years ago she had broken her nose. She was found in bed in a highly dyspnoeic and cyanotic state. Her toothless mouth was closed tightly and the nostrils were sucked in. The nasal mucosa was swollen. A nasal airway was introduced and the symptoms resolved within five minutes.

Case 3-An 89 year old woman was transferred to the nursing centre in a weak condition after having been admitted with gastric haemorrhaging. One evening she was found to be feverish and severely dyspnoeic and cyanotic. The nostrils were sucked in during inspiration and her toothless mouth was closed tightly. Again a disposable catheter alleviated the obstruction. The nasal septum was deviated and the mucosa was swollen. She suffered three more episodes the same night. Three days later she died of bronchopneumonia.

Case 4-A 78 year old woman with heart failure, extreme polyarthrosis, and a general loss of strength was receiving frusemide, prazosin, haloperidol, and promethazine (as a hypnotic). She remained bedridden, ate poorly, and developed a decubitus ulcer.
Several days before her death she became cyanotic with tightly closed toothless mouth and pinched in nostrils. Nasal catarrh and a deviated nasal septum were found. A nasal catheter was introduced but was removed by the patient. The nose was taped so that the nostrils could not be pulled inwards by suction; the patient did not protest.

Case 5-An 88 year old woman who had suffered a complete stroke was receiving digoxine and dytaurese. In the past she had broken her nose. She had neither teeth nor dentures. One week before her death she developed a respiratory tract infection. She ate and drank little and became bedridden. The next day she suffered an episode similar to those experienced by the patients in case 1-4. There was no recurrence. She died of aspiration pneumonia.

\section{Comment}

Since 1984 five women in this centre have been found suffering from dangerous oronasal obstruction: a tightly closed mouth without teeth and dentures, sucked in nostrils, a deviated nasal septum, and swollen nasal mucosa. They were bedridden, cachectic, and dehydrated but not unconscious. They did not raise the alarm. Three of them were in a terminal phase. Though a restrictive medical policy is followed in such cases, the obstruction can easily be eliminated with a disposable catheter.

Upper airway obstruction may occur when, in addition to imperfect patency of the nose, inspiratory suction is greater than the ability of the oropharyngeal muscles to keep the mouth and throat open. In babies with small upper airways this phenomenon can be observed during sleep and can lead to their sudden death' ${ }^{2}$; factors other than suction within the nose, mouth, and throat can also contribute to sudden infant death. ${ }^{3}$ Weak senile patients can suffer this oronasal obstruction even while awake if there is also a catarrhal inflammation of the nose and a pre-existing deviated nasal septum. Though the oral cavity is softer without teeth or dentures, it is not clear why patients with nasal obstruction do not breathe through the mouth The first patient (like the others usually a nasal breather) did this on another occasion when her nose was carefully blocked by pinching. 1 Klein M, Reynolds LG. Relief of sleep related oropharyngeal airway obstruc-
tion by continuous insufflation of the pharynx. Lancet 1986;i:935-9.
2 Guilleminault Ch, Heldt G, Powell N, Riley R. Small upper airway in near miss
sudden infant death syndrome infants and their families. Lancet 1986;i:402-7.
3 Milner AD. Recent theories on the cause of cot death. Br Med $\mathcal{F}$ 1987;295:
1366-8.

(Accepted 24 May 1988) 